\title{
Editorial
}

\section{O ensino de leitura em diferentes perspectivas}

\author{
Isabel Cristina Michelan de Azevedo* \\ icmazevedo2@gmail.com \\ http://orcid.org/0000-0002-5293-0168
}

\author{
Alberto Roiphe ${ }^{* *}$ \\ roiphea@gmail.com \\ https://orcid.org/0000-0002-7421-6993
}

\author{
Paulo Roberto Gonçalves-Segundo*** (ii) \\ paulosegundo@usp.br \\ https://orcid.org/0000-0002-5592-8098
}

Este número especial da revista Linha D'Água destacou em sua chamada o interesse em publicar uma edição com trabalhos que abordam a leitura em distintas abordagens teóricas e metodológicas, realizadas no âmbito do Mestrado Profissional em Letras (Profletras), por ser observável o crescente valor dessa prática de linguagem na sociedade contemporânea.

Desde o início desse projeto de mestrado em rede, em 2013, professores e pesquisadores observam que nos espaços sociais, incluindo os digitais, ocorre continuamente a integração de várias linguagens, o que exige dos estudantes o processamento de elementos verbais e não verbais em diferentes situações comunicativas associadas às variadas práticas de leitura. Assim, nesta edição (v. 34, n. 3), os leitores encontram dez artigos e um relato de experiências que apresentam reflexões relativas aos diferentes usos de linguagens na sociedade brasileira.

Acompanhar essas reflexões possibilita perceber que a leitura, tomada como um processo cada vez mais complexo, quando articulada a diferentes atividades didáticopedagógicas, requer dos estudantes o reconhecimento de palavras e sentenças, a produção de sentidos a partir de variadas referências contextuais e ideológicas, a articulação entre texto e imagem, indicando a diversidade das metodologias que podem favorecer o desenvolvimento de aprendizagens na escola e em outros espaços sociais.

\footnotetext{
* Universidade Federal de Sergipe (UFS), São Cristóvão, SE, Brasil.

** Universidade Federal do Estado do Rio de Janeiro (UNIRIO), Rio de Janeiro, RJ, Brasil.

*** Universidade de São Paulo (USP), São Paulo, SP, Brasil.
}

\section{LINHA DÁGUA}


Essas características têm gerado o interesse de investigadores de diferentes campos, como a Linguística, a Psicologia, a Educação, as Artes; por isso, os artigos e o relato analisam como os fundamentos teóricos se articulam a estratégias específicas voltadas ao aprimoramento do ensino-aprendizagem da leitura, em alinhamento aos documentos normativos em vigência no país, como a Base Nacional Comum Curricular (BNCC) e a Matriz de referência da Prova Brasil.

Isso pode ser observado a partir da primeira discussão, empreendida por Maria Aparecida Garcia Lopes Rossi, no artigo intitulado "Práticas de leitura em Língua Portuguesa a partir da BNCC: em que se fundamentam e como realizá-las em sala de aula?", que reconhece inicialmente a ausência de bases teóricas na BNCC para subsidiar o planejamento dos professores de educação básica empenhados em realizar um trabalho pedagógico consistente no eixo leitura em Língua Portuguesa com turmas de $6^{\circ}$ a $9^{\circ}$ anos do ensino fundamental. Em seguida, com base em uma pesquisa documental, reúne orientações direcionadas a apoiar as ações docentes em diferentes ambientes escolares.

Por sua vez, o artigo "Relações entre estratégias metacognitivas de leitura e desempenho escolar: possibilidades para o ensino de leitura", produzido por Maria Clara Maciel de Araújo Ribeiro, Thiago Loyola Franco e Anne Caroline Lima Campos, analisa as estratégias metacognitivas de leitura, tomadas em perspectiva sociocognitiva, que podem colaborar com o aprimoramento de habilidades de leitura. Como tais habilidades são requisitadas de estudantes com alto e baixo desempenho escolar, matriculados no ensino médio, o trabalho auxilia a entender a composição e as exigências de avaliações em larga escala realizadas periodicamente no Brasil. Os resultados evidenciam a interrelação entre o domínio da leitura, a metacognição e o desempenho escolar.

A preocupação com os níveis de leitura também suscitou o interesse de Raíssa Martins Brito e Maria Angélica Freire de Carvalho, que, no artigo "Níveis de compreensão leitora em um livro didático de Língua Portuguesa: uma análise sobre perguntas de leitura", investigou o monitoramento da compreensão textual a partir das atividades encontradas em uma obra aprovada pelo Programa Nacional do Livro Didático (PNLD). Com base nos pressupostos da Linguística Textual, as autoras indicam que as perguntas se alinham à compreensão literal e inferencial e raramente possibilitam a condução crítica por meio da integração do contexto extralinguístico.

O quarto artigo, "Da leitura subjetiva para a leitura rigorosa: um caminho para abordar leitura na Educação Básica”, escrito por Bruna Francinett Barroso Faustino e Sulemi Fabiano Campos, está pautado em uma pesquisa que descreve as dificuldades de leitura e de escrita de estudantes do Ensino Fundamental (Anos Finais) de uma escola pública e discute como a leitura e a escrita em contextos de mensagens em redes sociais têm influenciado tais práticas em sala de aula. Para fazer frente a isso, a pesquisa avaliou o quanto as narrativas literárias, linguística e estruturalmente complexas, motivam a construção de experiências de leitura para além das práticas utilitaristas.

\section{LINHA DÁGUA}


Em seguida, Raquel Cristina de Souza e Souza e Luiz Felipe Andrade Silva, no artigo "Hábito de leitura, confinamento e relações de classe: forma-leitura no Brasil contemporâneo", descrevem como foi possível incentivar o hábito de leitura de crianças afetadas pela pandemia de Covid-19. Com base em uma experiência de análise comparativa de matérias veiculadas na internet, observou-se que é preciso rever o modelo burguês de leitor, que explicita as relações de classe no Brasil contemporâneo, quando se quer desenvolver o prazer de ler.

O sexto artigo, intitulado "Leitura argumentativa na escola: propostas didáticas fundadas na perspectiva interacional da argumentação", elaborado por Isabel Cristina Michelan de Azevedo, Louriane Ribeiro Reis e Nadija Santos Monte, direciona o olhar para a especificidade da leitura argumentativa, por meio de duas pesquisas intervencionistas, realizadas em investigações desenvolvidas no Profletras, entre 2018 e 2019. Apoiadas no modelo dialogal da argumentação, as experiências didático-pedagógicas permitiram compor seis princípios orientadores para o desenvolvimento desse tipo de leitura na educação básica.

"Desenvolvimento de capacidades discursivas e cidadania no PIBID”, produzido por Ana Cecilia Teixeira Gonçalves, Jeize de Fátima Batista e Demétrio Alves Paz, é um artigo que traz reflexões a partir de duas experiências realizadas no âmbito do Programa Institucional de Bolsa de Iniciação à Docência (PIBID), tendo o texto literário como instrumento para o ensinoaprendizagem de Língua Portuguesa na Educação Básica. Assumindo como embasamento discussões sobre a formação inicial de professores e sobre leitura, o artigo evidencia ações que contribuem para a prática discursiva em sala de aula, chamando atenção, portanto, para a leitura, a análise, a interpretação, a reflexão e a produção textual, todas elas realizadas a partir de dois textos, o romance Dom Casmurro, de Machado de Assis, e o conto "As mãos dos pretos", de Luís Bernardo Honwana.

$\mathrm{Na}$ sequência, "Videoclipe no ensino médio e o desafio de integrar os modos semióticos", de Flávia Azambuja, Clara Dornelles e Taíse Simioni, é um artigo que analisa práticas de leitura e interpretação de um videoclipe por parte de estudantes do ensino médio. Os dados para análise foram obtidos a partir de uma tarefa elaborada para WebQuest e de atividades realizadas em sala de aula, registradas em áudio e, depois, transcritas. O referencial teórico apresenta o videoclipe como gênero discursivo e contribui para a discussão sobre as complexidades envolvidas na leitura multimodal.

No bojo das discussões que analisam a presença do livro na escola, o artigo "Quatro atos para ler e agir: a obra de teatro na perspectiva de ensino dos (multi)letramentos", organizado por Larissa Minuesa Pontes Marega, Everton Luis Paulino Vinha e Zilda Gaspar de Oliveira Aquino, apresenta uma sequência didática organizada para o último ano do ensino fundamental, tendo como foco a leitura da peça A megera domada, de William Shakespeare, a partir da concepção de texto dramático e dos conceitos de letramento literário e de multimodalidade.

\section{LINHA DÁGUA}


Na sequência, o artigo "As imagens de João Grilo em sua peleja argumentativa pelas veredas do Sertão: uma proposta de ensino-aprendizagem retórico-interacionista a partir da obra Auto da Compadecida", de Camila Alderete Capitani, propõe o desenvolvimento da capacidade de os sujeitos utilizarem-se da argumentação e da contra-argumentação no ambiente escolar, tendo como fundamentação a perspectiva retórico-interacionista.

Por fim, o relato intitulado "O diário de leitura: subjetividade na sala de aula", de Sheila Oliveira Lima, Patrícia Cardoso Batista e Tatiele Jesus Faria, apresenta o resultado de experiências didático-pedagógicas realizadas na Educação Básica e no Ensino Superior, considerando-se o diário como um instrumento que acolhe as impressões de leitura dos estudantes. $\mathrm{O}$ texto mostra de que forma o diário pode se tornar uma oportunidade para que o estudante seja protagonista do ato de ler, levando-se em conta a relação que estabelece com a obra, acessada pelo professor, ainda que todo o processo seja subjetivo.

Instrumento para a divulgação de trabalhos científicos, uma revista acadêmica, em virtude das contribuições docentes que recebe, também abre espaço para reflexões sobre o ensino e a aprendizagem relacionadas a diferentes áreas do conhecimento e variadas perspectivas teóricas.

Neste número, a Linha D'Água tem como foco o ensino e a aprendizagem de leitura na sua relação com os estudos linguísticos, discursivos, argumentativos e multimodais. Considerando, no entanto, a alta receptividade da chamada, que contou com contribuições muito diversas, tanto em termos de objetos de estudo quanto de abordagens teóricometodológicas, o dossiê se estende ao próximo número da revista, voltado ao ensino e à aprendizagem da leitura literária.

Desejamos a todas e a todos uma boa leitura!

São Paulo, dezembro de 2021. 